\title{
El conflicto saharaui durante la Transición. La controversia de Juan Goytisolo en la revista Triunfo y El País
}

The Sahrawi Conflict during the Spanish Transition. Goytisolo's Controversy in Triunfo and El País

\section{JosÉ MARTíNEZ RUBiO}

UNIVERSITÀ Di BOLOGNA (ITALIA) · jose.martinez@unibo.it

Doctor en Literatura Española por la Universitat de València y es lector de español y profesor contratado en la Università di Bologna. Miembro del grupo de investigación Artelope-TC/12 Consolider y TEMPUS-IDELE, y miembro de la red europea de investigadores "La memoria novelada". Ha publicado recientemente: El futuro era esto. Crisis y rematerialización de la Modernidad (Orbis Tertius, 2014) y Las formas de la verdad. Investigación, docuficción y memoria en la novela hispánica (Anthropos, 2015).

Resumen: Durante la Transición española a la democracia, la sociedad española asistió a un profundo debate sobre el derecho de autodeterminación del Sáhara Occidental. Los partidos de izquierda, intelectuales demócratas y autoridades franquistas apoyaron la independencia de la antigua colonia española. Sin embargo, Juan Goytisolo participó en la discusión desde Triunfo y El País con una postura que causó una gran controversia y diversas reacciones. Este artículo analiza los argumentos del debate durante aquellos años.

PALABRAS ClaVE: Juan Goytisolo, Western Sahara, RASD, Triunfo, Transición.
ABSTRACT: During the Spanish Transition to Democracy, the Spanish society witnessed a profound debate about the right to self-determination of Western Sahara. The left parties, democrats intellectuals and Franco authorities supported the independence of the Spanish colony. However, Juan Goytisolo participated in the discussion from Triunfo and El País with a point of view that caused a huge controversy and several reactions. This article analyzes the arguments of the discussion during those years.

KEY WORDS: Juan Goytisolo, Western Sahara, RASD, Triunfo, Transición 
En los últimos años, el conflicto desatado durante los setenta en el Sáhara Occidental y anquilosado en el tiempo por los países implicados y la incapacidad de desbloqueo político de Naciones Unidas, ha sido objeto de significativos estudios en materia de derechos humanos y de recuperación de testimonios en el campo de la memoria histórica. El 30 de octubre de 2007 el juez Baltasar Garzón se declaró competente para investigar un supuesto caso de genocidio en el Sáhara (Cembrero, 2007); ese mismo caso llevó al juez de la Audiencia Nacional Pablo Ruz en abril de 2015, ocho años después, a procesar a once altos cargos militares marroquíes ${ }^{1}$ (Pérez, 2015) por supuestos crímenes de lesa humanidad, y llevó también a José de la Mata, sustituto del juez Ruz en la causa, a procesar en mayo de ese mismo año a Lehsan Chaf Yeudan, carcelero del cuartel de Smara en el momento en que se produjeron los hechos investigados.

Junto a estos avances judiciales de la última década, de extraordinaria importancia para quien sigue de cerca el conflicto saharaui y de suma relevancia en cuanto a política exterior, ha sido destacable en ese mismo lapso de tiempo la publicación del informe El oasis de la memoria. Memoria histórica y violaciones de los Derechos Humanos en el Sáhara Occidental (2012), de los profesores Carlos Martín Beristain y Eloísa González Hidalgo, informe cofinanciado por el Gobierno Vasco y por la Agencia Vasca de Cooperación para el Desarrollo. Este informe, en la línea por ejemplo del informe Rettig en Chile y los sucesivos en Chile o Argentina, sitúa el caso saharaui en la órbita de aquellas sociedades que han sufrido un proceso traumático de carácter histórico-político (una dictadura o una ocupación militar) y que buscan verdad, justicia y reparación para las víctimas de violaciones de los Derechos Humanos, según explican los autores:

La historia que se cuenta en estas páginas ha permanecido en el corazón y la experiencia de muchas víctimas saharauis durante todos estos años. Muchas veces por la imposibilidad de poner en palabras el horror vivido. Otras porque se considera parte del camino que tantos y tantas han compartido. No es la historia de las negociaciones del Frente POLISARIO y el Reino de Marruecos, ni de la dejación de España, ni de los intereses internacionales en juego. Aunque está provocada por todo ello. Es la historia de la gente que ha sufrido las consecuencias de la violencia y el impacto de la persecución política cada vez que han reivindicado de forma pacífica la autodeterminación o han cuestionado al poder establecido. [...] Esta no es una historia contra nadie. Es una historia que tiene que ser escuchada y tenida en cuenta para la búsqueda de salidas políticas al conflicto, la gobernabilidad de la región y el respeto a los derechos humanos en el Magreb. (Martín Beristain y González Hidalgo, 2012: 15-18)

\footnotetext{
${ }^{1}$ Los once altos mandos militares procesados son Driss Sbai (coronel mayor de la Gendarmería Real), Brahim Ben Sami (interventor del director de Policía Judicial), Hariz El Arbi (comisario), Lamartiel (coronel), Abdelhafid Ben Hachemy (exgobernador de la Administración Territorial del Sáhara hasta 1997), Abdelhak Lemdaour (excoronel de las Fuerzas Armdas), Said Oussaou (exgobernador de Smara entre 1976 y 1978), Hassan Uychen (subgobernador de la provicnia), Muley Ahmed Albourkadi, Bel Laarabi y Abdelghani Loudghiri.
} 
En el campo cultural, pese al advenimiento del llamado boom de la memoria que ha rastreado y sacado a la luz numerosas historias del pasado traumático español (Becerra, 2015), el conflicto saharaui, que pertenece también a la memoria histórica española, ha sido escasamente atendido por los diferentes registros de la narrativa española (Luengo, 2012). Pese a ello (o precisamente por ello) son de especial relevancia las novelas El imperio desierto (1992) de Ramón Mayrata, o Mira si yo te querré (Premio Alfaguara de Novela, 2007) de Luis Leante ${ }^{2}$, la colección de cuentos editada por Mayrata, Relatos del Sáhara español (2001) o el ensayo de Tomás Bárbulo La historia prohibida del Sáhara español $(2002)^{3}$. Tuvo una gran aceptación y reconocimiento el documental dirigido por Álvaro Longoria y producido y protagonizado por Javier Bardem Hïos de las nubes. La última colonia (2012), que mereció el Premio Goya a la mejor película documental en 2013, así como Hammada de Anna Bofarull (2009) o El problema. Testimonio del pueblo saharaui, multipremiado documental de Jordi Ferrer y Pablo Vidal (2010). El propio título del cómic de Jaime Martín, Las guerras silenciosas, publicado en 2014 (en su versión en español; en francés, Les guerres silencieuses, 2013) ya indica tanto el desconocimiento en su momento como el olvido posterior de los conflictos que el franquismo mantuvo con sus colonias africanas, en el caso de Martín al relatar la experiencia de su padre en la guerra del Ifni (1957-1958) por lo que todas estas manifestaciones artísticas vendrían a recuperar la memoria de la presencia colonial

\footnotetext{
${ }^{2}$ Ambas novelas son analizadas por Ana Luengo en uno de los pocos artículos dedicados al tema desde el análisis literario: "La memoria de la vergüenza o los restos del imperio: la representación literaria del conflicto en el Sáhara Occidental en la novela contemporánea” (2012).

${ }^{3}$ Por los datos y títulos que aporta es interesante el estudio de Antonio Carrasco González La novela colonial hispanoafricana: las colonias africanas de España a través de la historia de la novela (2009). También por su voluntad de inventariar los títulos que van apareciendo sobre cuestiones coloniales y africanistas, aunque haría falta aplicar un filtro de calidad o de capacidad de proyección al elenco de novelas, es interesante el blog que el propio autor mantiene.

${ }^{4}$ La representación de la guerra de Ifni que elabora Jaime Martín en Las guerras silenciosas se basa en un borramiento del conflicto colonial con los territorios africanos. Si bien Martín reconstruye la violencia del ejército franquista, como epítome de toda una sociedad totalitaria, esa violencia se dirige hacia los propios militares, incidiendo más bien poco en los efectos sobre la población sometida y configurando el territorio colonial como un espacio de aventuras y de peligros. Cfr. Martínez Rubio, José (2016). Es significativa la coincidencia en los últimos años de obras y películas sobre la dominación española en África. Cabe destacar la reciente película Palmeras en la nieve, dirigida por Fernando González Molina, basada en la novela homónima de Luz Gabás (2012) y estrenada el 25 de diciembre de 2015. Si la novela fue un éxito de ventas, la recaudación de la película superó la primera semana de 2016 a la esperadísima Star Wars. El despertar de la fuerza, y superó la cifra de 2 millones de espectadores en apenas un mes en cartelera.
} 
española en territorios africanos, y a reflejar los problemas derivados del lamentable (e inacabado) proceso de descolonización del Sáhara Occidental en el que España tuvo un papel fundamental ${ }^{5}$.

Asistimos en la actualidad al lento proceso de recuperación de las distintas memorias del conflicto, a través de la cultura más comprometida y a través de meras ficciones que retratan el pasado español en el continente. Esta recuperación se suma a las noticias que llegan con cuentagotas sobre los refugiados (el caso de Aminetu Haidar en 2009, cuando la activista saharaui estuvo 32 días en huelga de hambre tras haber sido expulsada ilegalmente de El Aaiún por la policía marroquí; la catástrofe humanitaria sufrida en los campos de Tinduf a causa de las lluvias torrenciales de octubre de 2015), sobre los distintos procesos judiciales o sobre las diferentes negociaciones diplomáticas (las sucesivas prórrogas del mandato de la MINURSO en la zona; el inicio en 2012, por primera vez en Europa, de las discusiones en el Parlamento de Suecia para el reconocimiento de la República Árabe Saharaui Democrática como Estado y rechazado por el Ministerio de Exteriores del país a comienzos de 2016 debido al bloqueo por parte de Rabat a la implantación de la primera tienda Ikea en Marruecos ${ }^{6}$ ).

Como contribución a esta tarea de recuperación (o de resistencia al olvido) es muy pertinente rescatar el enorme interés y la enorme polémica que el conflicto saharaui despertó entre la intelectualidad española en los años setenta, especialmente entre la intelectualidad de izquierdas. Los argumentos y explicaciones divergentes provocaron auténticas series sobre el conflicto en la prensa de la época, reportajes, artículos de opinión, cartas, réplicas y contrarréplicas, acusaciones enconadas y

${ }^{5}$ En el conflicto España sigue teniendo un papel fundamental todavía hoy. El Secretario General Adjunto de Asuntos Jurídicos de la ONU, en una carta enviada al Presidente del Consejo de Seguridad fechada a 29 de enero de 2002 como informe sobre la licitud o ilicitud de la explotación por parte de empresas extranjeras de las minas de fosfatos de Bucraa en el Sáhara Occidental, reconoce que España sigue siendo potencia administradora del territorio. En el punto sexto afirma: "El 14 de noviembre de 1975 España, Marruecos y Mauritania emitieron en Madrid una declaración de principios sobre el Sáhara Occidental (el “Acuerdo de Madrid”), con arreglo al cual las facultades y responsabilidades de España, como Potencia administradora del Territorio, se transfirieron a una administración temporal tripartita. El Acuerdo de Madrid no transfirió la soberanía sobre el Territorio ni confirió a ninguno de los signatarios la condición de Potencia administradora, condición que España, por sí sola, no podía haber transferido unilateralmente". Y en el punto séptimo, confirma: "El 26 de febrero de 1976, España informó al Secretario General de que, con efecto a partir de esa fecha, había puesto fin a su presencia en el Sáhara Occidental y renunciado a sus responsabilidades respecto del Territorio, dejándolo así de hecho bajo la administración de Marruecos y Mauritania en las zonas que cada uno de ellos controlaba. Tras el retiro de Mauritania del Territorio en 1979 y la concertación del acuerdo mauritano-saharaui de 19 de agosto de 1979 (S/ 13504, anexo I), Marruecos ha administrado el Territorio del Sáhara Occidental por sí sólo. Marruecos, sin embargo, no figura como la Potencia administradora del Territorio en la lista de Territorios no autónomos de las Naciones Unidas y, por consiguiente, no ha transmitido la información sobre el Territorio prevista en el apartado e) del Artículo 73 de la Carta de las Naciones Unidas". (Corell, 2002).

${ }^{6}$ El País. 
José Martínez Rubio. El conflicto saharui...

defensas encendidas de posiciones y personajes, conformando una extraordinaria controversia que se desarrolló durante algo más de un lustro, en paralelo a las noticias sobre los acontecimientos bélicos del Sáhara Occidental. Una de las personalidades sobre las que giró buena parte de la polémica sobre el conflicto fue el escritor Juan Goytisolo, Premio Cervantes 2014, quien por entonces ya se había convertido en una figura controvertida e incómoda, tanto para el régimen franquista (que lo censuró) como para la oposición democrática (cuyos postulados no siempre fueron compartidos por el escritor).

\section{Juan Goytisolo, entre lo español y lo magrebí}

Mucho se ha hablado del carácter autobiográfico de la narrativa de Juan Goytisolo. Desde las memorias Coto vedado (1985) o En los reinos de taifa (1986), hasta las novelas con una presumible voluntad de ficción, en cuyos personajes se vislumbran las trazas y rasgos del propio autor: Señas de identidad (1966) o Reivindicación del conde don Julián (1970) en época relativamente temprana, o mucho más tarde Telón de boca (2003). En todas ellas, bien desde el apego hacia la referencialidad de los géneros memorísticos, bien desde la sugerente ambigüiedad entre la ficción y la realidad, se pueden rastrear los pasos vitales de Goytisolo a través de su literatura: el ambiente castrante de la dictadura franquista, el exilio en París, la relación con Monique Lange, la experimentación con la homosexualidad, la adhesión a las ideas comunistas, la ruptura con el castrismo tras su paso por Cuba, el contacto con el mundo árabe y con la sociedad marroquí, el eterno sentimiento de apátrida o de exiliado, etcétera. Como sostiene Diana Checa Vaquero: "En cada una de sus propuestas literarias [Goytisolo] proyecta una diferente forma de autorrepresentarse, variando la manera en que lleva a cabo este propósito" (Checa Vaquero, 2016: 207) ${ }^{7}$. La autodefinición que diera de sí mismo en Señas de identidad, una autoproyección ya clásica, resume su incapacidad para la identificación con identidades dadas, estables y reconocibles:

Castellano en Cataluña, afrancesado en España, español en Francia, latino en Norteamérica, nesrani en Marruecos y moro en todas partes, no tardaría en volverme a consecuencia de mi nomadeo y viajes en ese raro espécimen de escritor no reivindicado por nadie, ajeno y reacio a agrupaciones y categorías. (Goytisolo, 1999: 44-45)

\footnotetext{
7 Y continúa la cita: “Así, encontramos parodias de sí mismo a modo de 'autobiografías grotescas' en Paisajes después de la batalla (1982) y su continuación El exiliado de aquí y allá (2008); vemos la categoría autorial diseminada por todo el texto en El sitio de los sitios (1995) y en Las semanas del jardín (1997); exhibe en sus textos la presencia de personajes travestidos como en Carajicomedia (2000) y El exiliado de aquí y allá; o se fusiona o proyecta como personaje en autores de una tradición literaria muy escogida, tal como hace en Las virtudes del pájaro solitario (1988) al amparo de San Juan de la Cruz”. (Checa Vaquero, 2016: 207)
} 
La identidad en Goytisolo se muestra, de este modo, "huidiza y constituyente, existiendo únicamente en tránsitos, sin llegar a obtener un significado unificador" (Veljović, 2014: 209). Resulta revelador constatar que tanto Señas de identidad, como Reivindicación del conde don Julián tuvieron que ser publicadas en México en 1966 y 1970 respectivamente, de modo que el escritor no pudo ser tal en su patria de origen; este hecho abundará en esa sensación de rechazo del escritor, quien se considerará "el autor español probablemente más perseguido por los rigores de la censura franquista en los últimos quince años” (1979: 132). El rechazo sufrido se tornará a su vez rechazo de una "españolidad" cerrada. Esta incapacidad de identificación con una patria, con una raza o con un lugar, hará que la literatura compense ese vacío; no por casualidad, su propia peripecia vital, sus conflictos con el entorno, las ausencias del padre y de la madre, su exilio, su sexualidad nada convencional, ocuparán un espacio central en su literatura. En palabras de Jennifer Gronau, "en los textos de Goytisolo, la literatura se convierte en un 'lieu de mémoire’ donde otros ‘lieux de mémoire’ fracasan” (Gronau, 2011: 223). El propio escritor, en la cumbre del reconocimiento literario durante el discurso de entrega del Premio Cervantes 2014, destaca la mirada periférica de su vida y de su obra:

A comienzos de mi larga trayectoria, primero de literato, luego de aprendiz de escribidor, incurrí en la vanagloria de la búsqueda del éxito -atraer la luz de los focos, "ser noticia", como dicen obscenamente los parásitos de la literatura- sin parar mientes en que, como vio muy bien Manuel Azaña, una cosa es la actualidad efímera y otra muy distinta la modernidad atemporal de las obras destinadas a perdurar pese al ostracismo que a menudo sufrieron cuando fueron escritas.

La vejez de lo nuevo se reitera a lo largo del tiempo con su ilusión de frescura marchita. El dulce señuelo de la fama sería patético si no fuera simplemente absurdo. Ajena a toda manipulación y teatro de títeres, la verdadera obra de arte no tiene prisas. [...]

Desde la altura de la edad, siento la aceptación del reconocimiento como un golpe de espada en el agua, como una inútil celebración. Mi condición de hombre libre conquistada a duras penas invita a la modestia. La mirada desde la periferia al centro es más lúcida que a la inversa. (Goytisolo, 2014)

Desde esta condición "nómada", compartida precisamente por los habitantes del Sáhara, Goytisolo observa desde una perspectiva muy particular los acontecimientos que suceden en el Sáhara Occidental en los años setenta. Por un lado, el exilio y su oposición a la dictadura franquista hacen imposible toda vinculación con los postulados del régimen: en un primer momento colonialistas y en un segundo momento independentistas. Pero no solo por su ideología antifranquista, sino también (y sobre todo) el acercamiento a las realidades del Magreb, bien en Francia, bien en Marruecos, sus constantes viajes a Marrakech, donde se instalará definitivamente en los años noventa, y su conocimiento del mundo árabe, harán que su posición con respecto al conflicto marroquí-saharaui tampoco encaje con las posiciones de la izquierda española, encarnada por el PCE y el PSOE. Estos apoyarán 
programáticamente el derecho de autodeterminación del pueblo saharaui durante el proceso de descolonización y durante el conflicto bélico, coincidiendo con los albores de la democracia recuperada.

El bienio que va de 1974 a 1976 resulta crucial en este conflicto. En 1974, el Partido Socialista Obrero Español en el Congreso de Suresnes asume el derecho de autodeterminación de los pueblos que integran España. En noviembre de 1975 se producen en un lapso de dos semanas tres acontecimientos fundamentales: el 6 de noviembre, la Marcha Verde, la marcha de ocupación popular y militar marroquí del Sáhara Occidental auspiciada por el rey Hassan II; el 14 de noviembre, la firma del Acuerdo Tripartito de Madrid, donde España cede la administración del territorio a Marruecos y Mauritania; el 20 de noviembre, la muerte del dictador Francisco Franco. El 26 de febrero de 1976, las últimas tropas españolas se retiran del Sáhara, y esa misma noche la República Árabe Saharaui Democrática es proclamada por el Frente Polisario, el movimiento de liberación creado en 1973 para luchar por la descolonización e independencia del Sáhara. Trazando un paralelismo perverso, al tiempo que España inicia su proceso de Transición a la democracia, el territorio que hasta hace pocas semanas (e incluso pocos días) pertenecía al Estado español ha pasado a formar parte de otras administraciones, la marroquí y la mauritana, habiéndose suplantado una dominación por otra, según las tesis del Polisario.

A partir de ese momento, arreciará el debate sobre la gobernabilidad del Sáhara, la independencia, la autonomía o la integración en Marruecos (las tres vías de gobierno). Los partidos de izquierdas, todavía en la clandestinidad, igualarán el derecho del pueblo español a un sistema de elecciones libres con el derecho del pueblo saharaui a decidir en votación sobre su status quo. De hecho, Felipe González, elegido Secretario General en el Congreso de Suresnes de 1974, viajará en 1976 a los campamentos de refugiados de Tinduf y mostrará su apoyo expreso a la causa saharaui y a la dirección del Frente Polisario. Tal apoyo será mucho más discreto durante los años de gobierno felipista (1982-1996), aunque la autodeterminación del Sáhara Occidental aparecerá en documentos, resoluciones y manifestaciones del Partido Socialista hasta la actualidad ${ }^{8}$.

Desde el lado opuesto, el régimen franquista coincidirá con las posiciones de la izquierda clandestina y apoyará la autodeterminación del Sáhara Occidental. Sus motivaciones serán bien distintas: la administración militar del territorio, junto al principio sagrado (para el franquismo) de unidad e indisolubilidad de la patria española, harán que el Sáhara sea considerado en un principio provincia española; cuando los organismos internacionales instan a la metrópolis a descolonizar el Sáhara, un territorio con derecho de autodeterminación; y finalmente, cuando los acontecimientos de noviembre de 1975 se precipitan, una colonia española abandonada y entregada con vergüenza al Reino de Marruecos y Mauritania. Tanto la humillación de la retirada de la administración militar, como la imposibilidad de

\footnotetext{
${ }^{8}$ Cfr. Carme Chacón: “La posición de los socialistas sobre el Sáhara no ha cambiado”.
} 
continuar influyendo en la región en un plano económico o geopolítico, serán dos de las razones para que las fuerzas franquistas reivindiquen la libertad del Sáhara, o para que al menos lamenten la anexión a Marruecos.

En este contexto, Juan Goytisolo, exiliado de un país y de numerosos dogmas, tan libre como expulsado de todo convencionalismo, será el artífice de toda una polémica de gran repercusión al defender desde "un sentido elemental de justicia [...] las aspiraciones legítimas del pueblo marroquí” (Goytisolo, 1979: 132) ${ }^{9}$. Ello le obligará a enfrentarse no solo al pensamiento de izquierdas hegemónico, sino también al consenso entre las diferentes ideologías en España sobre la cuestión del Sáhara.

\section{Los debates en la revista Triunfo y el diario EI País}

Dos de los medios en que se desarrolló todo este debate sobre el conflicto saharaui fueron la revista Trünfo y el diario El País. Triunfo había nacido en 1946 como semanario cultural, pero no sería hasta su refundación en 1962 cuando aparecería el primer número de la revista que había de convertirse en el medio de referencia para los intelectuales de izquierdas (Bellomi, 2011). En ella escribían pensadores de la talla de Eduardo Haro Tecglen, Manuel Vázquez Montalbán, Manuel Vicent o Fernando Savater, y colaboraban con ilustraciones satíricas los dibujantes Quino o Chumy Chúmez, algunos de los cuales (y otros muchos) estaban en la órbita (si no en las filas) del PCE. La revista Trünfo publicó su último número en 1982, abarcando en total más de tres décadas de historia de España y en especial elaborando una crítica "desde dentro" de las fronteras nacionales durante los años sesenta y setenta. El diario El País, en cambio, apareció después de la muerte del dictador, el 4 de mayo de 1976, y ya desde los años de la Transición se convirtió en la voz y en el referente de las ideologías progresistas y de los partidos democráticos ${ }^{10}$, hasta convertirse rápidamente en el diario generalista más leído en España.

Ambos medios gozaban de un gran prestigio entre las clases intelectuales y un gran seguimiento del gran público, de modo que las informaciones aparecidas y los debates publicados entre sus páginas

\footnotetext{
${ }^{9}$ Aunque resulte paradójico, radicalmente diferente es la posición de Goytisolo con respecto a Palestina, sobre cuya situación se ha expresado en términos de "ocupación de Israel” y para la que ha reclamado el cumplimiento de los Derechos Humanos y las resoluciones del Consejo de Seguridad de la ONU: "el Holocausto no justifica la permanente humillación que condena a los palestinos a vivir en su propia tierra bajo un régimen de apartheid, que viola todas las resoluciones del Consejo de Seguridad de las Naciones Unidas y las leyes internacionales establecidas en su Texto Fundacional”. Cfrd. El País.

${ }^{10}$ Mientras otros diarios como $A B C$ o La Vanguardia habían continuado con su actividad informativa bajo el régimen de Franco, El País o Diario 16 nacieron en 1976 con una clara orientación democrática.
} 
alcanzan a revelar la importancia de los diferentes temas en la sociedad española. Algunas cifras al respecto pueden ayudar a calibrar la importancia del conflicto saharaui en la España de la segunda mitad de los setenta.

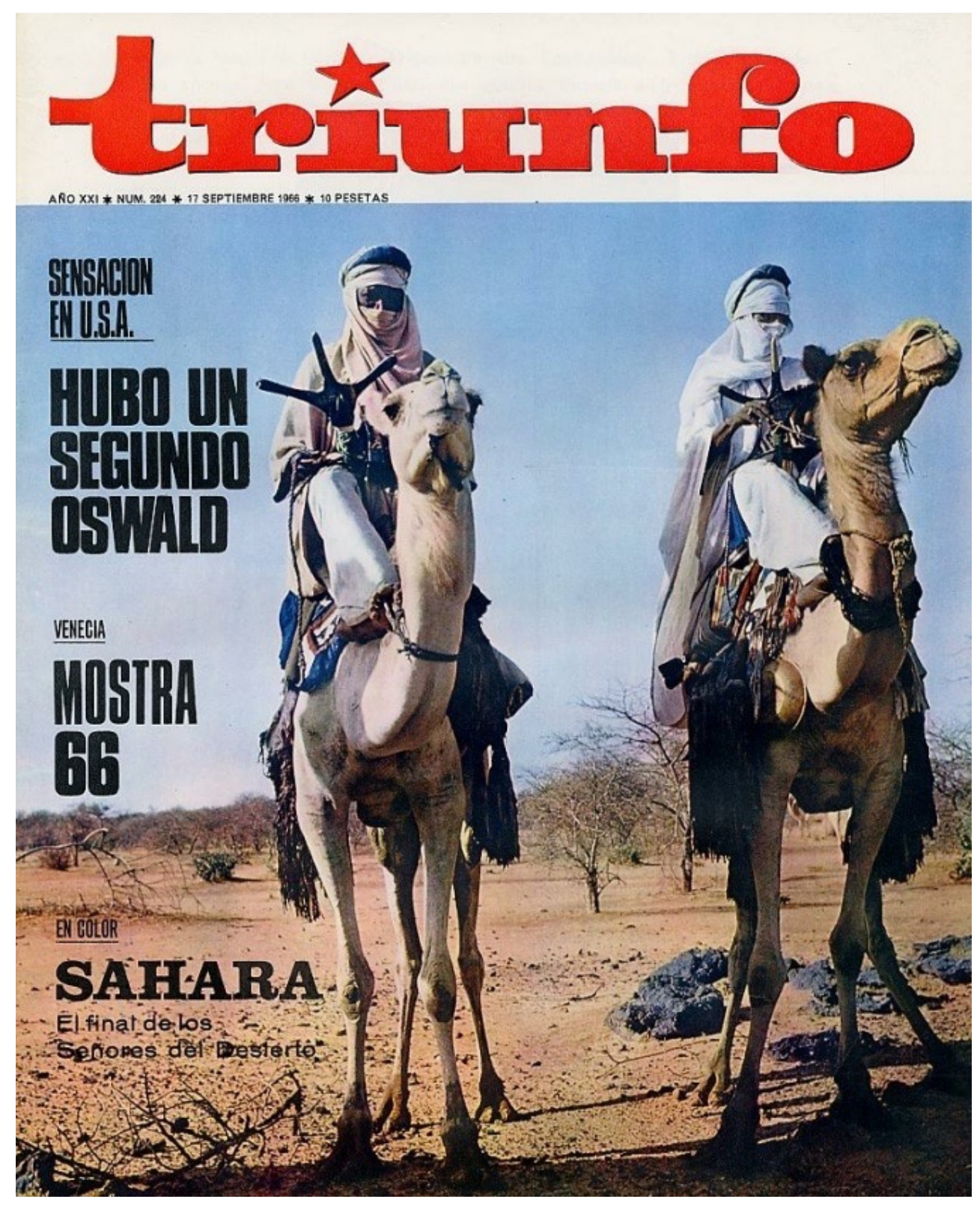

Revista Triunfo 1966 
Hasta noviembre del 75, Triunfo solo había publicado un reportaje sobre el Sáhara Occidental ${ }^{11}$ : en el año 1966 apareció el reportaje "Sahara: el final de los señores del desierto", un reportaje sobre los últimos tuaregs, tribu guerrera y con costumbres y organización feudales que estaba sucumbiendo a la administración moderna del territorio, al trazado y cierre de fronteras en África y a la extensión de la vida sedentaria. Este reportaje, folklorista y exótico, estaba acompañado de vistosas fotografías de J. M. RuizZardoya, pero nada explicaba de las tensiones políticas y sociales de la colonia española. No obstante, a partir del estallido del conflicto se sucedieron las noticias, reportajes y artículos de opinión: en 1975 aparecieron cuatro sobre la relación de Marruecos con Mauritania o los Estados Unidos a propósito del Sáhara Occidental; en 1976, las publicaciones subieron a ocho ${ }^{12}$; en 1977, a nueve; en 1978, a once publicaciones sobre el conflicto; en 1979, a seis; en 1980, una sola, la última de todas antes del cierre del semanal. Las cifras contrastan con la atención dedicada por el semanario, por ejemplo, a la actividad de la banda terrorista ETA ${ }^{13}$ en los años de plomo, en el mismo periodo en que sobre el Sáhara se escriben un total de 39 artículos, sobre ETA aparecen un total de nueve ${ }^{14}$, datos que demostrarían el fuerte interés por el conflicto en la sociedad española del momento.

La hemeroteca del diario El País también ofrece datos muy elocuentes al respecto. El primer número del periódico, publicado el 4 de mayo de 1976, contenía dos noticias sobre el conflicto saharaui. Durante todo ese primer mes de existencia, se publicaron hasta 20 textos sobre el tema. Y entre ese 4 de mayo del 76 hasta el 31 de diciembre de 1979, coincidiendo con el punto álgido de la atención de Triunfo, se recogen un total de 1257 entradas, entre noticias, artículos de opinión, reportajes, cartas, etc. Para comprobar la importancia del conflicto saharaui otorgada por El País en el debate público, basta con comparar estos datos con los datos arrojados por la hemeroteca sobre algunos de los elementos o figuras claves de la transición española en el periodo 04/05/1976 - 31/12/1979: ETA (2340 entradas), Adolfo Suárez (1928 entradas), Juan Carlos I (1781 entradas), Santiago Carrillo (777 entradas), GRAPO (748 entradas), Felipe González (737 entradas). El tema saharaui, por lo tanto, tiene un interés de primer orden durante la segunda mitad de la década de los setenta y se le otorga una importancia a la altura de los grandes procesos que está viviendo el país, coincidiendo además con un

\footnotetext{
11 Para hacer un cálculo del gran interés que despertó el tema, véase Anexo 1.

12 Incluida la polémica de Juan Goytisolo.

13 Véase anexo 2.

${ }^{14}$ Exclusivamente sobre terrorismo de ETA son nueve artículos. Los descriptores de la revista triunfo, en cambio, muestran 118 resultados para una amalgama muy dispar de artículos sobre el País Vasco durante estos años: autonomismo, izquierda abertzale, centrales nucleares, bilingüismo, conformación de ayuntamientos, ley de amnistía, etc.
} 
periodo de enorme complejidad política en España, de violencia de extrema derecha y extrema izquierda, y de incertidumbre por el proceso de cambio político hacia la democracia.

En este ambiente y en estos dos medios Juan Goytisolo, con las credenciales que hemos descrito, removió con sus escritos las aguas de la intelectualidad española. Ya en diciembre de 1974, un año antes de que se precipitaran los acontecimientos, el escritor había escrito un artículo en Le monde diplomatique ${ }^{15}$ reclamando, desde el propio título una "auténtica independencia" para el Sáhara Occidental. En este "Pour une authentique indépendance" Goytisolo denunciaba la manipulación que la potencia colonial española estaba operando en la colonia y en la metrópolis para crear un estado de opinión favorable a la celebración de un referéndum de autodeterminación para el territorio:

Au cours des dernières semaines, après la divulgation du projet de statut élaboré par le gouvernement de Madrid «pour mener à terme le processus d'évolution du Sahara occidental vers l'autodétermination» au moyen d'un référendum en 1975, conformément aux résolutions de 1969 et 1972 prises par l'ONU, nous assistons à une campagne d'intoxication dont le propos, sinon le langage, s’inscrit dans la vieille tradition du colonialisme espagnol. (Goytisolo, 1974: 36)

Este extraño reconocimiento de derechos del régimen franquista buscaría, en opinión del autor, una presumible independencia del Sáhara que pudiera estar controlada de facto por el poder económico español (aunque ya no político). Esta misma tesis fue la defendida por el primero de los artículos publicado en la revista Triunfo en dos partes, el 8 de mayo de 1976 y el 15 de mayo de 1976, bajo el título "La izquierda española, los nacionalismos magrebís (sic) y el problema del Sáhara" 16.

En este artículo, como prevención ante los argumentos y críticas que le sobrevendrán más tarde Goytisolo comienza declarándose seguidor del régimen argelino en lugar del régimen marroquí. Argelia había conquistado su independencia de Francia en 1962 bajo las reivindicaciones y las luchas del Frente de Liberación Nacional, un movimiento político independentista, revolucionario, antiimperialista y tercermundista; frente a Argelia, Marruecos conservaba en el poder a la monarquía alauita que representaba, para el mundo occidental, una posición conservadora, e incluso reaccionaria.

Para que quede bien clara mi intención en el asunto, precisaré ab initio que mis simpatías políticas e ideológicas van hacia la Revolución Argelina y no hacia el Régimen actual de Marruecos. Dichas simpatías, agregaré, no son de ahora, pues se remontan al período en que el

\footnotetext{
${ }^{15}$ Cfr. Juan Goytisolo: "Pour une authentique indépendance".

16 Tanto "La izquierda española, los nacionalismos magrebís (sic) y el problema del Sáhara" (Triunfo, 08-15/05/1976) como “El Sáhara, dos años después” (El País, 17-26/05/1978), "Respuesta a Costa Morata con el Sáhara al fondo” (El País, 05/10/1978), “Ceuta y Melilla: la política del avestruz” (El País, 02/02/1979) fueron recogidos por el autor en un volumen titulado El problema del Sáhara publicado por Anagrama en 1979. Cito los susodichos artículos por esta edición.
} 
José Martínez Rubio. El conflicto saharui...

pueblo argelino combatía, en condiciones extremadamente difíciles, por su libertad e independencia. Durante los primeros años de mi exilio involuntario en París fui testigo de las violencias racistas contra la masa obrera argelina residente en Francia (detenciones arbitrarias, asesinatos, torturas, toque de queda, etcétera), así como de la lucha clandestina del FNL contra tales atropellos y brutalidades, y me enorgullezco de decir que, junto con muchos otros simpatizantes europeos, colaboré, muy modestamente, en el movimiento de resistencia. (1979: 21-22)

No obstante, esta afinidad ideológica de Goytisolo hacia Argelia, paradigma de la emancipación colonial africana de las potencias europeas, chocaba con la posición de Huari Bumedián, presidente de Argelia entre 1965 y 1978, con respecto al Sáhara Occidental. Argelia había apoyado las independencias de Guinea-Bissau, Angola y Mozambique, y ahora apoyaba la autodeterminación del pueblo saharaui. Esta posición sin embargo no provenía, en opinión del escritor, del carácter tercermundista del gobierno de Bumedián sino de un interés por el control geopolítico de la región: si Marruecos se anexionaba el territorio del Sáhara, controlaría los yacimientos de fosfato de Bucraa y los recursos naturales del lugar, convirtiéndose en potencia hegemónica del Magreb; el interés, según Goytisolo, para apoyar la creación de la República Árabe Saharaui Democrática sería el de impedir la dominación de Marruecos en la región:

La tensión actual entre Marruecos y Argelia no obedece [...] a una confrontación ideológica entre un gobierno progresista y un régimen "reaccionario" por una cuestión de principio (el de la autodeterminación del pueblo saharaui): es el enfrentamiento puro y simple (como en el caso de China y de la URSS) entre un nacionalismo hasta ahora frustrado y otro que, no contento con la enorme porción que el colonialismo francés le asignó [...], aspira a ejercer una posición hegemónica en el Magreb. (1979: 54-55)

Siguiendo el razonamiento de Goytisolo, el eje ideológico izquierda - derecha por el cual Argelia representaría los anhelos de la izquierda internacionalista y Marruecos la derecha capitalista no serviría para explicar el conflicto saharaui.

Bumedián ha intentado, con éxito, disfrazar este conflicto de intereses (el choque de dos nacionalismos opuestos) inscribiéndolo en el cuadro más general de la actual confrontación entre las fuerzas progresistas y reaccionarias, dándole un carácter ideológico e internacionalizándolo. Pero, desdichadamente, la tercera realidad de los hechos desmiente este enfoque. (1979: 55)

La izquierda española, uno de los tres pilares sobre los que construirá su argumentación el autor ya desde el título del artículo, estaría analizando el conflicto desde posiciones ideológicas, es decir, equivocadas: la disputa por el Sáhara Occidental no sería más que una lucha entre naciones o nacionalismos, y el Frente Polisario, un partido o movimiento de corte progresista, financiado y apoyado por Argelia, jugaría ese doble papel, el de reivindicación de la izquierda y del principio de autodeterminación del Sáhara, y a la vez el impedimento de la expansión de Marruecos. 
Goytisolo se retrotrae al periodo de la II República, donde el PCE y el PSOE de los setenta hunden sus raíces ideológicas, para examinar la relación de la izquierda española (o izquierdas) con Marruecos y la cuestión colonial. No duda el escritor en calificarla de "chovinista, abiertamente racista" (27), "paternalista" (30), "condescendiente" (31) o que camina en ese proceso de descolonización "con las mismas anteojeras que antaño" (29).

Para Juan Goytisolo es inconcebible la coincidencia de posiciones entre la izquierda española, antifranquista y en favor de la democracia en España y en África, con el totalitarismo del régimen de Franco.

Cuando el franquismo lanzó la idea de autodeterminación del Sáhara, nuestros partidos de oposición desaprovecharon la oportunidad que se les brindaba para denunciar, de acuerdo con la izquierda marroquí, el carácter cínico y oportunista de su maniobra. El Sáhara no les interesaba, y todavía en el programa de lanzamiento de la Junta Democrática, de julio del 74, no figura la menor mención al problema. (1979: 29-30)

Juan Goytisolo acusa a la izquierda española en estos términos: desde la ignorancia para analizar los problemas del Magreb o el eurocentrismo para encontrar soluciones, hasta el mero desinterés por la cuestión, la mera "ignorancia" (65) o el simple y llano aprovechamiento de la coyuntura descolonizadora para presentarse ante el electorado como partidos comprometidos con la autodeterminación de los pueblos. Esta impostura de las izquierdas será denunciada por el propio Goytisolo en un artículo posterior, "Ceuta y Melilla: la política del avestruz", publicado en el diario El País el 2 de febrero de 1979, en el que reclama ese mismo derecho de autodeterminación para las plazas de soberanía en África, hasta día de hoy negado por cualquier gobierno español del siglo XX o XXI.

Si es furibundo el ataque hacia la izquierda, no más piadosa será la opinión hacia la derecha española. Para el escritor, la salida de la administración española de su colonia es "el amargo fruto de veinte años de errores, dilaciones, quimeras, autoengaño" (1979: 45) y no duda en calificar de "fracaso rotundo" (45) su presencia en la zona y la humillante decisión de abandonar el lugar. Pero aparte de estas dolorosas consideraciones, Goytisolo explica el cambio de postura del régimen de Franco al pasar de la exaltación de la hispanidad del Sáhara a promover en instancias internacionales el derecho de autodeterminación del pueblo saharaui:

El objetivo de la nueva política [franquista] consiste en organizar un referéndum que desemboque en la creación de un Estado saharaui y sustituir así la ocupación colonial abierta con una entidad fantoche que, en razón de su misma inviabilidad, debería colocarse, a las buenas o a las malas, bajo la tutela del Régimen de Madrid. Sin Ejército, sin Administración, sin infraestructura económica, sin técnicos, sin experiencia, con un territorio extenso y apenas habitado, el futuro Estado saharaui devendría automáticamente, conforme a los deseos de sus padrinos, en un apéndice o marioneta de España. (1979: 37-38) 
El nuevo Estado saharaui que pretende la España de Franco sería, en opinión de Goytisolo, una prolongación de la dominación colonial de España. Estas características, la ingobernabilidad del territorio o la debilidad de la administración independiente, conducirían a "la imposibilidad de crear sobre tales bases una entidad independiente y [...] enfrentada ab initio a la hostilidad de sus vecinos, sin la ayuda e intervención de un tercero, llámese España o Argelia" (48) y alerta sobre la "balkanización" (54) de la región si florecen estados independientes al calor de reivindicaciones identitarias, ideológicas o coyunturales.

No escatima Goytisolo en argumentos de diversa índole para sostener sus tesis: desde la original voluntad del Sáhara Occidental de unión con Marruecos (en 1956 hubo una asamblea con 5000 delegados que pedían la expulsión de la administración española y la unión con Marruecos; 1979: 35); la negación de una identidad saharaui correspondiente a un solo territorio (extiende lo saharaui también a territorio mauritano o argelino); la creación por parte de España del problema y de la "identidad" saharaui (47); la necesidad de una ocupación de las fuerzas del orden españolas en mayor número que la población nativa para garantizar un hipotético referéndum (40); la connivencia del Frente Polisario con las autoridades franquistas (42); la imposibilidad de elaborar un censo real de ciudadanos saharauis (47-48); la ambigüedad e incoherencia de los diplomáticos del Polisario a la hora de defender un status quo independiente (51-52) y el aprovechamiento de la causa saharaui de todo tipo de gente ajena al conflicto, desde altos representantes que no hablan español hasta argelinos que huyen de la sequía y se instalan en los campamentos de Tinduf (51-52); el papel contradictorio e interesado de Bumedián con respecto al Sáhara Occidental, y agresor con respecto a Marruecos (53); la escasa "credibilidad internacional" de la República Árabe Saharaui Democrática (60).

Mucho más indulgente se muestra Goytisolo hacia los acontecimientos provenientes del Reino de Marruecos. La marcha verde, la operación de ocupación con que los marroquíes entraron en territorio saharaui alentados por el monarca Hassan II para pedir la expulsión de los españoles y asumir la administración del territorio, es calificada de "entusiasmo popular" (31) o de "marroquís indefensos, partícipes entusiastas de la Marcha Verde" (46). Junto al entusiasmo de la población marroquí, es inapelable el sentimiento patriótico del país ocupante: "la fuerza del sentimiento nacional marroquí, el hecho de que ningún Régimen de Marruecos iba a aceptar jamás la creación de una entidad estatal en el Sáhara" (47). A la aceptación de este estado de cosas desde la óptica marroquí, Goytisolo lo llamará "realismo político" (62) y será toda explicación y justificación para los acontecimientos de noviembre del 75. Junto al entusiasmo y al nacionalismo de Marruecos, Goytisolo maneja la falacia de la inevitabilidad:

Mientras el realismo político impondrá a los argelinos la aceptación de la actual división del Sáhara entre Mauritania y Marruecos, obligará igualmente a los nacionalistas marroquís a admitir definitivamente el status quo de las presentes fronteras de su país con Argelia. La implantación 
José Martínez Rubio. El conflicto saharui...

marroquí en el ex Sáhara español es tan irreversible como la implantación de Argelia en la inmensa zona desértica que le otorgó Francia. (1979: 62)

Con este análisis de la situación, la posición de Goytisolo no solo justifica la anexión del Sáhara Occidental en el Reino de Marruecos, sino que especula con la creación de una entidad magrebí supranacional.

La Historia, la razón, la justicia, los intereses, obligarán un día u otro a los dirigentes marroquís y argelinos a sacrificar sus diferencias en aras del Magreb unido que los pueblos reclaman. Para entonces, Marruecos y Mauritania deberán haber ganado la verdadera paz y transformado su actual implantación militar y administrativa en el Sáhara Occidental en una cohabitación fraterna. Dicho objetivo lo lograrán tan solo si en vez de poner el énfasis en el control del territorio que recuperan, le (sic) ponen en los sentimientos de la desvalida y traumatizada población que los habita. (1979: 63)

La postura de Goytisolo en este primer artículo causó un enorme escándalo entre la intelectualidad de izquierdas, en un momento que, como hemos visto, el conflicto saharaui despertaba un enorme interés entre la sociedad española y desde posiciones enfrentadas se abogaba por un referéndum de autodeterminación. No solo los calificativos inmisericordes hacia la izquierda española, también levantaban ampollas conceptos como "recuperación" del territorio por parte de Marruecos en lugar de "ocupación", "cohabitación fraterna" en lugar de "genocidio" y "paz" (uno de los léimotivs del franquismo) inevitable a partir de la administración marroquí del territorio.

Como era previsible, las respuestas a estos planteamientos no se hicieron esperar.

\section{El eco de la polémica: Emilio Menéndez del Valle y Pedro Costa Morata}

Tras la publicación de "La izquierda española, los nacionalismos magrebís (sic) y el problema del Sáhara" de Juan Goytisolo en mayo de 1976, uno de los colaboradores de Triunfo que más atención había dedicado al conflicto se apresuró a rebatir al barcelonés a través de un artículo titulado "Juan Goytisolo, la izquierda española y la cuestión del Sáhara” y publicado en la misma revista el 19 de junio de $1976^{17}$. Emilio Menéndez del Valle había firmado o firmaría posteriormente en el semanario reportajes sobre Uganda, Guinea Ecuatorial, Sudáfrica o Namibia; había cursado estudios de Relaciones

\footnotetext{
17 Junto a los tres artículos publicados por Goytisolo ("La izquierda española, los nacionalismos magrebís y el problema del Sáhara", 1976; "El Sáhara, dos años después”, 1978; "Ceuta y Melilla: la política del avestruz", 1979), el libro recopilatorio El problema del Sáhara (Goytisolo, 1979) recoge tres anexos: el primero, este artículo de Emilio Menéndez del Valle; el segundo, la respuesta de Goytisolo a este, "El Sáhara y la izquierda española”; el tecero, la respuesta de Goytisolo a un artículo de Pedro Costa Morata que no aparece en el volumen pero que examinaré a continuación: "Respuesta a Costa Morata con el Sáhara al fondo”.
} 
Internacionales en la Universidad de Columbia y, durante los años ochenta, se dedicaría a labores diplomáticas como embajador en Jordania o Italia. De 1999 a 2014 sería elegido diputado por el Partido Socialista en el Parlamento Europeo, integrando delegaciones y comisiones de asuntos exteriores ${ }^{18}$.

Entre la admiración y la vehemencia, y aun acusándolo de hablar desde una perspectiva acomodada propia de una torre de marfil, Menéndez del Valle respondía a las acusaciones que Goytisolo había lanzado a la izquierda española y a los argumentos con que había defendido la ocupación de Marruecos, de facto, y una especulativa conformación del Gran Magreb. Como aludido ("porque en la izquierda me incluyo, en concreto en el Partido Socialista, sobre el que Goytisolo, al igual que sobre el PC, derrama chuzos de punta", Goytisolo, 1979: 120), no solo acepta las acusaciones de racismo que el escritor profiere hacia gobiernos de izquierdas en el pasado y su relación con el África colonial, sino que se demora en casos flagrantes a nivel español y a nivel europeo (como el racismo generalizado hacia los soldados marroquíes que intervinieron entre las filas del ejército para sofocar la Revolución de Asturias de 1934), y recupera el debate que los partidos integrantes de la Internacional Socialista mantuvieron entre el siglo XIX y XX a propósito de los territorios colonizados (con respecto a la India, Sudáfrica o el Congo, los distintos intelectuales marxistas no abogarán por su independencia). No obstante, arguye Menéndez del Valle, la izquierda que se enfrentaba al conflicto saharaui mantenía un discurso muy distinto al de la izquierda de entresiglos, habiendo asumido no solo las tesis de Marx sino las tesis complementarias de emancipación de los pueblos, entre ellas las tesis tercermundistas ${ }^{19}$. En otras palabras, lo que era achacable a la izquierda de los años veinte y treinta durante las guerras con Marruecos y la colonia, no eran achacable per se a una izquierda a favor del derecho de autodeterminación de (parte de) esas colonias:

Lo que le disgusta a Goytisolo -ferviente admirador de la entidad sociopolítica llamada Marruecos- es que la izquierda española actual haya tomado partido, son ambages, por la autodeterminación del pueblo saharaui [...]. Lo que lleva implícito el apoyo a las tesis progresistas y socializantes (no socialistas) de Argelia y de la República Árabe Saharaui Democrática. Y, consiguientemente, mientras no cambien las cosas en Rabat, el rechazo de la oligarquía que allí gobierna oprimiendo a su pueblo. Lo cual no excluye el reconocimiento de los errores del pasado. (1979: 123)

En este punto, Menéndez del Valle le da la vuelta a la argumentación de Goytisolo que pretendía desvincular las posiciones de Argelia con las posiciones de izquierda y la postura de Marruecos con la idea de imperialismo o reaccionarismo. A la llamada del escritor a que la izquierda española (y europea)

\footnotetext{
18 Véase su ficha de europarlamentario.

${ }^{19}$ Otro de los grandes debates dentro de la izquierda mundial fue la ampliación del concepto de emancipación del sujeto, no solo a través de las luchas de clase, sino también a partir de los conflictos de género o de dominación colonial y poscolonial.
} 
entendiera y se entendiera con la izquierda marroquí (nacionalista y a favor de la anexión del Sáhara Occidental) en pro de una emancipación de clase, el diplomático responde:

[En ese caso] la absorción del Sáhara y su manipulación por la oligarquía y gran burguesía marroquíes fortalecerían el seudonacionalismo (sic) y el trono alauita, al tiempo que retrasarín la verdadera liberación nacional y social. (1979: 126)

La réplica de Menéndez del Valle sigue punto por punto las controvertidas (y en absoluto populares) afirmaciones de Goytisolo. Con respecto al cuestionamiento de Argelia en la gestión del conflicto, del Valle entiende la lógica de intereses argelinos como dialéctica con los intereses marroquíes, y afirma asumiendo esta máxima: "yo opino que el argelino es uno de los sistemas menos malos del Tercer Mundo. Ello sin soslayar el hecho de que todavía los Estados tienen sus intereses y los pueblos los suyos" (128). Con respecto a las acusaciones de tibieza del Frente Polisario hacia España o de impostura al erigirse como representante de una voluntad independentista saharaui, la respuesta de Menéndez del Valle es firme: las circunstancias del Sáhara Occidental han cambiado hasta llegar a 1975, donde el Frente Polisario (aun con apoyo logístico y armamentístico de Argelia) es sostenido por su pueblo.

Diversas e importantes circunstancias han cambiado y nuevos elementos han surgido de 1956: hoy existe en Argelia un Régimen progresista y en Marruecos una Monarquía reaccionaria (inexistentes ambos en aquel año). En cualquier caso, toda comunidad tiene derecho a revisar sus postulados vitales y políticos. Y eso es lo que el F. Polisario -vanguardia representativa de la colectividad saharaui- ha hecho. No se puede negar que hoy por hoy, directa o indirectamente, consciente o inconscientemente, la mayor parte del pueblo sigue la vía polisaria. De ahí la masacre y la persecución del Ejército marroquí y de ahí la guerra de guerrillas que está en marcha y que cada día se incrementa. Y ninguna organización fantoche -sin vinculación real con el pueblo donde opera- puede llevar adelante ese tipo de guerra popular. (1979: 129)

En suma, la argumentación de Goytisolo se articulaba en torno a los problemas históricos de la colonia, al comportamiento de España, a los intereses de la metrópolis, a los intereses vecinos (principalmente de Argelia, no de Marruecos o Mauritania), a la lucha por la descolonización y al problema para elaborar un censo o establecer una identidad específica que no se diluya dentro de lo “magrebí”, y eludía cualquier referencia a los acontecimientos del 75 en términos de ocupación, ni aludía a ninguna de las situaciones de violación de los derechos humanos que la prensa sacaba a la luz cada semana. Por su parte, la réplica de Menéndez del Valle es más sincrónica y su postura está más contextualizada: las circunstancias de la región han cambiado y los intereses de cada Estado existen, pero hay una aspiración por encima de condicionantes históricos y acontecimientos del pasado: el derecho de autodeterminación en las circunstancias concretas de 1975.

La respuesta de Juan Goytisolo a Emilio Menéndez del Valle titulada "El Sáhara y la izquierda española” (Triunfo, 10/07/1976) volvía sobre los pasos de la primera carta. Con un léxico muy 
significativo, justificaba las "aspiraciones legítimas del pueblo marroquî" (132) y negaba a España y Argelia toda posición de mediación en el conflicto:

Si Argelia no tiene reivindicación territorial alguna respecto al ex Sáhara español su intervención militar en el territorio y su reconocimiento de la República Saharaui no pueden justificarse ni en nombre del noble principio de autodeterminación de los pueblos ni por razones de vecindad geográfica: del mismo modo que Madrid no puede defender con un mínimo de credibilidad su justa reivindicación anticolonialista de Gibraltar sin dar previamente ejemplo, procediendo a la descolonización de las llamadas plazas de soberanía de la costa africana [Ceuta y Melilla], Argelia no se halla en condiciones de exigir de Marruecos el respeto a un principio que ella misma se ha guardado muy bien de aplicar en su propia casa. (135)

Y mirando siempre hacia un horizonte tan ideal como ficticio de emancipación de la clase obrera en un Gran Magreb con Argelia, Marruecos, Mauritania, Túnez y Libia formando una sola unidad administrativa, Goytisolo alude directamente a los motivos de índole económico para la posesión de Marruecos del territorio saharaui:

El triunfo de la empresa independentista [...] habría privado a dieciséis millones de marroquís de una de las mayores bazas económicas de que hoy disponen para salir algún día del subdesarrollo [los recursos naturales del Sáhara Occidental, las zonas pesqueras y los yacimientos de fosfato de Bucraa]. Una vez liquidado el contencioso actual para bien de los pueblos del Magreb [...] las fuerzas y movimientos de izquierda de Marruecos deberán enfrentarse a gravísimos y urgentes problemas interiores: lucha contra la miseria e ignorancia, por la democracia, justicia social y control popular sobre los actos y opciones de poder, etc. (1979: 141)

La política de hechos consumados que plantea Goytisolo por un lado al reconocer la importancia del territorio saharaui para la economía marroquí, junto a la vehemencia de su argumentación y la hoja de ruta falaz de emancipación de los pueblos del Magreb, encendió todavía más el debate. Dos años después, entre el 17 y el 26 de mayo de 1978, el escritor publicó una serie de artículos en el diario El País ordenados bajo el título precisamente de: "El Sáhara, dos años después". En esta serie venía a repetir algunas de sus tesis ya planteadas en 1976: el conflicto no estaba motivado por una lucha de signo ideológico opuesto, sino por el choque de "dos nacionalismos hermanos y adversos" (72) al que España se sumaría en calidad de potencia interesada en crear un Estado fantasma fácilmente controlable (77).

Lo significativo dos años después es la atención que Goytisolo dedica al número de refugiados saharauis asentados en Tinduf, y el desprestigio que teje a propósito de ese censo imposible a propósito de las noticias e informaciones que llegan desde Argelia. Tras penosos cálculos, el escritor sentencia con toda la crudeza del léxico: "Un simple cálculo de viviendas abandonadas en El Aaiún, Smara, Bojador y Dajla establecido por testigos imparciales en enero de 1976 [...] nos permite cifrar el número aproximado de fugitivos entre veinte y treinta mil" (79). Y acusa a Argelia de: 
José Martínez Rubio. El conflicto saharui...

hacer pasar por refugiados del Sáhara Occidental no solo a sus propios erguibats sino también a decenas de miles de tuaregs, chaambas y otros nómadas procedentes de Mali y aún del Níger que abandonaron sus habituales zonas de pastoreo a consecuencia de la dramática sequía del Sahel. (1979: 79)

Complica aún más, eso sí, la identificación de la identidad saharaui con un único Estado, al abrir a consideraciones de tribus la pertenencia o no al territorio conocido como Sáhara Occidental: según este razonamiento, las "tribus saharauis" en otro tiempo nómadas estarían desperdigadas por el Sáhara, Mauritania y Argelia y toda reivindicación de territorio debería absorber parte de esos Estados vecinos.

Ante el dramatismo creciente del conflicto saharaui, agravado entre 1976 y 1978 tanto dentro de las zonas ocupadas como la zona de conflicto o los en los campos de refugiados, Goytisolo deprecia el "turismo revolucionario" (75) de la izquierda española y sigue reclamando que España no asuma las tesis independentistas de Argel y que favorezca la pacificación de la región aun a costa de las reivindicaciones del Polisario.

Este texto dos años después, que no sería tanto un balance de la situación como una repetición de argumentos minoritarios en un debate público muy encendido, tuvo a su vez una réplica en forma de serial firmado por Pedro Costa Morata. Pedro Costa Morata se había interesado parcialmente por cuestiones africanistas y había mantenido colaboraciones en El País y en Trünfo a propósito de cuestiones medioambientales; no por casualidad años más tarde sería cabeza de lista por Izquierda Unida defendiendo postulados ecologistas. No deja de ser curioso que las dos reacciones más significativas provengan de Emilio Menéndez del Valle, eurodiputado socialista, y de Pedro Costa Morata, candidato en su momento de Izquierda Unida; ambos representarían aquella izquierda institucional que defenestraba Juan Goytisolo en su primer escrito.

Tanto en "Reivindicación de la causa saharaui" (El País, 29/08/1978) como en "El gran Marruecos, un sueño nacional-fascista" (30/08/1978), “La fobia anti-argelina" (31/08/1978), "Las izquierdas paralelas" (01/09/1978), “Autodeterminación, ¿sí, pero no?” (02/09/1978) o "Los inalienables derechos del pueblo saharaui” $(11 / 10 / 1978)$, su autor se empleaba con crudeza contra Goytisolo y su defensa del Estado que había usurpado el territorio saharaui, violado los derechos humanos en la zona y provocado el éxodo de parte de su población hacia Tinduf. Desde su misma retórica marxista, Costa Morata defendía los postulados del Polisario y atacaba al escritor de manera casi personal:

Ha de señalarse la serie (véase EL PAIS, días 17-26 de mayo) que desarrolló Juan Goytisolo en torno al tema del Sahara exponiendo, con evidente brillantez, los argumentos de la postura marroquí. Para mí, el mayor éxito de las tomas de posición del escritor se cifra en la incapacidad de respuesta que viene suscitando. 
José Martínez Rubio. El conflicto saharui...

No creo que la influencia de Argelia sobre los "turistas revolucionarios invitados" (entre los que me cuento, de vez en vez), sea mayor que la de Marruecos sobre los intelectuales afincados y halagados de Fez, Tánger o Marrakech.

Creo que, por lo demás, el sentimiento independentista entre el pueblo saharaui se ha afirmado. No fueron los franquistas ni los corrompidos del PUNS, los que provocaron este sentimiento ni lo delimitaron. El Frente Polisario ya era, por tradición y por ideología, una fuerza progresista seria(que, por cierto, no recibió apoyo argelino hasta bien entrado 1975). Dar más valor a las reivindicaciones nacionalistas de los años 50 (Istiqlal), que a la decisión independentista saharaui de los años 70 (Polisario), no se justifica políticamente; es una cuestión de elección, por la motivación que sea. (Costa Morata, 1978)

A pesar de la supuesta incapacidad de respuesta, lo cierto es que Goytisolo sí recibió críticas razonadas tanto en Triunfo como en El País por parte de especialistas en la materia. Y si bien Costa Morata defiende la causa saharaui en términos sincrónicos, como Emilio Menéndez del Valle, aduciendo que los tiempos han cambiado y las reivindicaciones de los setenta no son las mismas que en los cincuenta, Goytisolo se refugia en los postulados del PPS (el Partido Comunista marroquí) y hace suyas las declaraciones de su líder, Ali Yata, para desactivar toda acusación de reaccionarismo:

Este movimiento nacional es un movimiento de liberación nacional progresista que no ha cesado nunca de combatir, por muchas que fueran las pruebas que debió sufrir. Fue este movimiento nacionalista el que tomó la iniciativa y se movilizó para recuperar una tierra -el Sáhara Occidental- que siempre fue marroquí. (1979: 146)

\section{El eterno debate}

Los razonamientos y acusaciones (en ocasiones, como hemos visto, de carácter personal) valieron para un fuego cruzado de artículos y reportajes entre especialistas en el Magreb que se combinaban dramáticamente con las noticias que la prensa reflejaba a diario. Entre 1976 y 1979 se produjo el gran debate social alrededor del Sáhara y se debatió con prolijidad cuál debía ser la posición de un Estado como España, todavía potencia administradora según la $\mathrm{ONU}^{20}$ y responsable en aquel momento de la situación traumática del pueblo saharaui. Los partidos de izquierda apostaron sobre la base de sus programas por la autodeterminación del Sáhara, y sin embargo tanto con el ascenso al poder del Partido Socialista como con el establecimiento de la Misión de las Naciones Unidas para el Referéndum del Sáhara Occidental (MINURSO) en 1991, el status quo de la zona ha continuado tal y como se dejó con la firma de paz con Mauritania en 1979 y el alto al fuego con Marruecos en 1991.

${ }^{20}$ Vid. Nota 5. 
El argumento que utilizaba Goytisolo para defender la postura promarroquí, la imposibilidad de establecer un censo ni de pobladores saharauis ni de refugiados en Tinduf, ha valido para eternizar el proceso de descolonización, hasta el punto que 2016 la MINURSO ha extendido su mandato para la celebración del referéndum de autodeterminación del Sáhara en 43 ocasiones ${ }^{21}$.

La normalización de la vida democrática en España durante los años ochenta (con sus convulsiones históricas) junto a la eternización del conflicto hicieron desviar el foco de atención de la antigua metrópolis sobre la antigua colonia. Con el proceso cultural de recuperación de la memoria histórica, sin embargo, y siguiendo los avatares judiciales de los últimos años, parece que el interés sobre la situación del Sáhara, la memoria del conflicto, el testimonio del trauma ${ }^{22}$ y la responsabilidad del Estado español ha devuelto cierto interés hacia un conflicto aún sin resolver. Sin embargo, hubo un tiempo en que el Sáhara despertó un debate de gran magnitud en la sociedad española, y que se desarrolló de manera muy combativa y con mayor precisión que en la actualidad. Valga también este texto como parte de esa recuperación de la memoria.

\footnotetext{
21 Véase el elenco de resoluciones de Naciones Unidas para la extensión de la Misión en el Sáhara.

22 Junto a la obra citada de Carlos Martín Beristain y Eloísa González Hidalgo, cabe destacar el estudio de Mustapha Mohamed Lamin Ahmed "El largo camino hacia la identidad saharaui. Testimonios de persecución y estrategias de construcción cultural: desde la oralidad a la literatura saharaui en español”, Trabajo Final de Máster presentado en la Universitat de València en septiembre de 2015.
} 
José Martínez Rubio. El conflicto saharui...

\section{Bibliografía}

Bárbulo, Tomás (2002). La historia prohibida del Sáhara español. Barcelona: Destino.

Becerra, David (2015). La guerra civil como moda literaria. Madrid: Clave Intelectual.

Bellomi, Paola (2011). Periodismo cultural y compromiso político. Las páginas literarias de Triunfo (1970-1978). Cáceres: Universidad de Extremadura. Servicio de Publicaciones.

Bofarull, Anna (2009), Hammada.

Carrasco González, Antonio (2009). La novela colonial hispanoafricana: las colonias africanas de España a través de la historia de la novela. Madrid: Sial.

Cembrero (2007), "Garzón investigará un supuesto genocidio en el Sáhara Occidental”. El País, $31 / 10 / 2007$.

Checa Vaquero, Diana (2016). "Juan Goytisolo y la reconstrucción de la identidad a través de la literatura: un viaje de ida y vuelta”. Enache, Irina; Martínez Rubio, José; Lakhdari, Sadi (eds.) Identidades inestables. Avatares, evoluciones y teorías de la subjetividad en la narrativa española actual. Paris: Indigo Côte-Femmes: 207-215.

Corell, Hans (2002). Carta de fecha 29 de enero de 2002 dirigida al Presidente del Consejo de Seguridad por el Secretario General Adjunto de Asuntos Jurídicos, Asesor Jurídico. Consejo de Seguridad de las Naciones Unidas.

Costa Morata, Pedro (1978). "Reivindicación de la causa saharaui”. El País, 29/08/1978.

Costa Morata, Pedro. (1978). “El gran Marruecos, un sueño nacional-fascista”. El País, 30/08/1978.

Costa Morata, Pedro (1978). "La fobia anti-argelina”. El País, 31/08/1978.

Costa Morata, Pedro (1978). “Las izquierdas paralelas”. El País, 01/09/1978.

Costa Morata, Pedro (1978). “Autodeterminación, ¿sí, pero no?”. El País, 02/09/1978.

Costa Morata, Pedro(1978). "Los inalienables derechos del pueblo saharaui”. El País, 11/10/1978.

Ferrer, Jordi y Vidal, Pablo (2010). El problema. Testimonio del pueblo saharaui, documental.

Gabás, Luz (2012). Palmeras en la nieve. Madrid: Temas de hoy.

González Molina, Fernando (2015). Palmeras en la nieve, película.

Goytisolo, Juan (1966). Señas de identidad. México, Joaquín Mortiz.

Goytisolo, Juan (1970). Reivindicación del conde don Julián, México, Joaquín Mortiz.

Goytisolo, Juan (1974). "Pour une authentique indépendance”, Le monde diplomatique, diciembre 1974. 
José Martínez Rubio. El conflicto saharui...

Goytisolo, Juan (1976). "La izquierda española, los nacionalismos magrebís y el problema del Sáhara”, Triunfo, 08-15/05/1976. Goytisolo, Juan (1979). El problema del Sáhara, Barcelona: Anagrama.

Goytisolo, Juan (1976). “El Sáhara y la izquierda española”, Triunfo, 10/07/1976. Goytisolo, Juan (1979). El problema del Sáhara, Barcelona: Anagrama.

Goytisolo, Juan (1978). “El Sáhara, dos años después”, El País, 17-26/05/1978. Goytisolo, Juan (1979). Elproblema del Sáhara, Barcelona: Anagrama.

Goytisolo, Juan (1978). "Respuesta a Costa Morata con el Sáhara al fondo”, El País, 05/10/1978. Goytisolo, Juan (1979). El problema del Sáhara, Barcelona: Anagrama.

Goytisolo, Juan (1979) “Ceuta y Melilla: la política del avestruz”. El País, 02/02/1979. Goytisolo, Juan (1979). Elproblema del Sáhara, Barcelona: Anagrama.

Goytisolo, Juan (1979). El problema del Sáhara. Barcelona: Anagrama.

Goytisolo, Juan (1985 [1999]). Coto vedado. Madrid: Alianza.

Goytisolo, Juan (1986). En los reinos de taifa. Barcelona: Seix Barral.

Goytisolo, Juan (2003). Telón de boca. Barcelona: Aleph Editores.

Goytisolo, Juan (2015). Discurso en la ceremonia de entrega del Premio Cervantes 2014. $23 / 04 / 2015$.

Gronau, Jennifer. “La utopía de la identidad. Representaciones de pérdida y construcción de identidad a través de los espacios ficcionales en la obra autobiográfica de Juan Goytisolo", Quaderns de Filologia. Estudis literaris, vol. XVI (2011): 211-224

Leante, Luis (2007). Mira si yo te querré. Madrid: Alfaguara.

Longoria, Álvaro (2012). Hijos de las nubes. La última colonia, documental.

Luengo, Ana. "La memoria de la vergüenza o los restos del imperio: la representación literaria del conflicto en el Sáhara Occidental en la novela contemporánea”, Revista Iberoamericana, XII, 48 (2012): 7-20.

Martín, Jaime (2013). Les guerres silencieuses. Paris: Dupuis.

Martín, Jaime (2014). Las guerras silenciosas. Barcelona: Norma Editorial.

Martín Beristain, Carlos y González Hidalgo, Eloísa (2012). Eloasis de la memoria. Memoria histórica y violaciones de los Derechos Humanos en el Sáhara Occidental. Universidad del País Vasco: Publicaciones de la Universidad del País Vasco. 
José Martínez Rubio. El conflicto saharui...

Martínez Rubio, José. “La memoria africana. Representaciones del Ifni en Las guerras silenciosas de Jaime Martín”, CELEHIS : Revista del Centro de Letras Hispanoamericanas, 31 (2016): 63-80.

Mayrata, Ramón (1992). El imperio desierto. Barcelona: Mondadori.

Mayrata, Ramón (2001). Relatos del Sáhara español. Madrid: Clan Editorial.

Menéndez del Valle, Emilio (1976). "Juan Goytisolo, la izquierda española y la cuestión del Sáhara”, Triunfo, 19/06/1976. Goytisolo, Juan (1979). El problema del Sáhara. Barcelona: Anagrama.

Mohamed Lamin Ahmed, Mustapha (2015). "El largo camino hacia la identidad saharaui. Testimonios de persecución y estrategias de construcción cultural: desde la oralidad a la literatura saharaui en español”. Trabajo Final de Máster presentado en la Universitat de València en septiembre de 2015.

Pérez (2015): “Ruz procesa a 11 mandos militares marroquíes por genocidio en el Sáhara”. El País, 09/04/2015.

Veljović, Jelica. "La constitución de la identidad marginada en Señas de identidad de Juan Goytisolo". Verba hispanica, XXII, 4 (2014): 197-212. 
Anexo 1. Artículos y reportajes publicados en la revista Triunfo entre 1966 y 1980 sobre el Sáhara Occidental y el conflicto saharaui. Datos extraídos de la web Triunfo Digital, proyecto de digitalización de todos los fondos de la revista Triunfo llevado a cabo en colaboración entre la Universidad de Salamanca (José Ángel Ezcurra) y Ediciones Pléyades S.A.

$1966(1)$

Título: "Sahara: el final de los señores del desierto"

Num: 224 Año: XXI

Fecha de publicación: 17-09-1966 Página(s):26-35

$1975(4)$

Autor: González, Fernando, 1948-1980

Título: "Marruecos: entre Gibraltar y el Sahara"

Num: 648 Año: XXIX

Fecha de publicación: 01-03-1975 Página(s):34-37

Autor: Haro Tecglen, Eduardo, 1924-2005

Título: "La ambición de Marruecos"

Num: 659 Año: XXX

Fecha de publicación: 17-05-1975 Página(s):6-7

Autor: Menéndez del Valle, Emilio, 1945-

Título: "El Sahara, España y los Estados Unidos"

Num: 666 Año: XXX

Fecha de publicación: 05-07-1975 Página(s):14-15

Autor: Menéndez del Valle, Emilio, 1945-

Título: "Cabo Verde, el Sahara y los Estados Unidos"

Num: 669 Año: XXX

Fecha de publicación: 26-07-1975 Página(s):8-11

$1976(8)$

Autor: Aguilar Navarro, Mariano, 1916-1992

Título: "El Sahara y el "Acuerdo de Madrid"”

Num: 676 Año: XXX

Fecha de publicación: 10-01-1976 Página(s):26-27

Título: "La tragedia del Sahara"

Num: 683 Año: XXX 
Fecha de publicación: 28-02-1976 Página(s):23-24

Autor: Goytisolo, Juan, 1931-

Título: "La izquierda española, los nacionalismos magrebis y el problema del Sahara". I

Num: 693 Año: XXX

Fecha de publicación: 08-05-1976 Página(s):46-51

Autor: Goytisolo, Juan, 1931-

Título: "La izquierda española, los nacionalismos magrebis y el problema del Sahara”. II

Num: 694 Año: XXX

Fecha de publicación: 15-05-1976 Página(s):40-45

Título:"El pueblo saharaui existe"

Num: 698 Año: XXX

Fecha de publicación: 12-06-1976 Página(s):36-37

Autor: Menéndez del Valle, Emilio, 1945-

Título: "Juan Goytisolo, la izquierda española y la cuestión del Sahara"

Num: 699 Año: XXXI

Fecha de publicación: 19-06-1976 Página(s):44-47

Autor: Goytisolo, Juan, 1931-

Título: "El Sahara y la izquierda española"

Num: 702 Año: XXXI

Fecha de publicación: 10-07-1976 Página(s):22-25

Autor: Costa Morata, Pedro, 1947-

Título: "III Congreso del Frente Polisario"

Num: 713 Año: XXXI

Fecha de publicación: 25-09-1976 Página(s):28-30

$1977(9)$

Autor: Costa Morata, Pedro, 1947-

Título: "Sahara: una guerra de desgaste"

Num: 732 Año: XXXI

Fecha de publicación: 05-02-1977 Página(s):18

Autor: Costa Morata, Pedro, 1947-

Título: "Conversaciones políticas con el Frente Polisario" 
Num: 735 Año: XXXII

Fecha de publicación: 26-02-1977 Página(s):24-25

Autor: Costa Morata, Pedro, 1947-

Título: "Sahara: primer aniversario de una República en armas"

Num: 738 Año: XXXII

Fecha de publicación: 19-03-1977 Página(s):21-23

Autor: Ramonet, Ignacio, 1943-

Título: "Una película por el Sahara: tendremos toda la muerte para dormir "

Num: 746 Año: XXXII

Fecha de publicación: 14-05-1977 Página(s):58-59

Autor: Costa Morata, Pedro, 1947-

Título: "El 4 aniversario del Frente Polisario"

Num: 749 Año: XXXII

Fecha de publicación: 04-06-1977 Página(s):18-19

Autor: González, Fernando, 1948-1980

Título: "La conferencia de la OUA"

Num: 754 Año: XXXII

Fecha de publicación: 09-07-1977 Página(s):66

Autor: Costa Morata, Pedro, 1947-

Título: "Ofensiva madrileña preotoñal”

Num: 764 Año: XXXII

Fecha de publicación: 17-09-1977 Página(s):17

Título: "Hassan II y la izquierda española"

Num: 773 Año: XXXII

Fecha de publicación: 19-11-1977 Página(s):17

Autor: Costa Morata, Pedro, 1947-

Título: "Mitología reaccionaria que trae la guerra"

Num: 773 Año: XXXII

Fecha de publicación: 19-11-1977 Página(s):16-17

$1978(11)$

Autor: Riz, Juan de la 
Título: "Un pueblo con voluntad de ser"

Num: 789 Año: XXXII

Fecha de publicación: 11-03-1978 Página(s):56-57

Autor Secundario: Ortega, Carlos

Autor: Rivero Ferrera, Carmelo, 1957-

Título: "Canarias: saharauis non gratos"

Num: 791 Año: XXXII

Fecha de publicación: 25-03-1978 Página(s):48-49

Autor Secundario: Rivero, Martín, 1956-

Autor: Márquez Reviriego, Víctor, 1936-

Título: "Apuntes parlamentarios:El milagro del Sahara"

Num: 791 Año: XXXII

Fecha de publicación: 25-03-1978 Página(s):16-17

Autor: Temprano Santos, Emilio, 1947-

Título: "Rodríguez de Viguri: los últimos días del ejército español en el Sahara"

Num: 796 Año: XXXII

Fecha de publicación: 29-04-1978 Página(s):26-30

Autor: Costa Morata, Pedro, 1947-

Título: "España nos abandona"

Num: 811 Año: XXXII

Fecha de publicación: 12-08-1978 Página(s):20-22

Autor: Costa Morata, Pedro, 1947-

Título: "Sahara: el estallido de la negación"

Num: 812 Año: XXXII

Fecha de publicación: 19-08-1978 Página(s):36-37

Autor: Costa Morata, Pedro, 1947-

Título: "UCD se va al desierto"

Num: 820 Año: XXXII

Fecha de publicación: 14-10-1978 Página(s):45

Autor: González, Fernando, 1948-1980

Título: "El plan 'Magreb' de Giscard"

Num: 821 Año: XXXII

Fecha de publicación: 21-10-1978 Página(s):35-37 
Autor: Costa Morata, Pedro, 1947-

Título: "Frente Polisario: ‘El acuerdo tripartito es un cadáver"”

Num: 826 Año: XXXII

Fecha de publicación: 25-11-1978 Página(s):45

Autor: Montánchez, Enrique, 1950-

Título: “¿Quién asesina frente al Sahara? “

Num: 828 Año: XXXII

Fecha de publicación: 09-12-1978 Página(s):52-53

Autor Secundario: López Boza, José

Autor: González, Fernando, 1948-1980

Título: "Sahara: Segundo movimiento"

Num: 829 Año: XXXII

Fecha de publicación: 16-12-1978 Página(s):60-61

$1979(6)$

Autor: Costa Morata, Pedro, 1947-

Título: "El irresistible ascenso de la causa saharaui"

Num: 841 Año: XXXIII

Fecha de publicación: 10-03-1979 Página(s):36-37

Autor: Costa Morata, Pedro, 1947-

Título: "Mauritania: la angustia de un estado fantasma"

Num: 855 Año: XXXIII

Fecha de publicación: 16-06-1979 Página(s):33

Autor: Maestre Alfonso, Juan, 1938-

Título: "Goytisolo y el Sahara"

Num: 859 Año: XXXIII

Fecha de publicación: 14-07-1979 Página(s):42

Título:" Hassan II: aislado por la OUA"

Num: 861 Año: XXXIII

Fecha de publicación: 28-07-1979 Página(s):34

Título: "La soledad de Marruecos"

Num: 865 Año: XXXIII 
José Martínez Rubio. El conflicto saharui...

Fecha de publicación: 25-08-1979 Página(s):27

Autor: Costa Morata, Pedro, 1947-

Título: "USA no quiere un 'Dien Bien Fu’ para Hassan”

Num: 874 Año: XXXIII

Fecha de publicación: 27-10-1979 Página(s):25

$1980(1)$

Autor: López García, Bernabé, $1947-$

Título: "Farsas y licencias de un rey castizo"

Num: 908 Año: XXXIII

Fecha de publicación: 21-06-1980 Página(s):38-39 
Anexo 2. Artículos y reportajes publicados en la revista Triunfo entre 1966 y 1980 sobre la actividad de la banda terrorista de ETA. Datos extraídos de la web Triunfo Digital, proyecto de digitalización de todos los fondos de la revista Triunfo llevado a cabo en colaboración entre la Universidad de Salamanca (José Ángel Ezcurra) y Ediciones Pléyades S.A.

1977

Autor: Erroteta, Peru, 1945-

Título: "Euskadi: el caso 'Box"”

Num: 733 Año:XXXI

Fecha de publicación: 12-02-1977 Página(s):34-35

Autor: Erroteta, Peru, 1945-

Título: "Secuestro y muerte de Javier de Ybarra o el ocaso de ETA"

Num: 753 Año:XXXII

Fecha de publicación: 02-07-1977 Página(s):8-9

Título: "ETA frente a Euskadi"

Num: 768 Año:XXXII

Fecha de publicación: 15-10-1977 Página(s):17

Autor: Erroteta, Peru, 1945-

Título: "Se multiplican las señales de alarma"

Num: 778 Año:XXXII

Fecha de publicación: 24-12-1977 Página(s):9

1978

Título: "El País Vasco y los crímenes de ETA"

Num: 821 Año:XXXII

Fecha de publicación: 21-10-1978 Página(s):14-15

Autor: González, Fernando, 1948-1980

Título: "Requiem incompleto por "Argala"”

Num: 831 Año:XXXII

Fecha de publicación: 30-12-1978 Página(s):20-21

1979

Autor: Haro Tecglen, Eduardo, 1924-2005 
José Martínez Rubio. El conflicto saharui...

Véase además: Aldebarán, Juan ; Pozuelo ; Berbén, Pablo ; Vara, Ignacio de la

Título: "El desafío al turismo"

Num: 858 Año:XXXIII

Fecha de publicación: 07-07-1979 Página(s):18-19

Título: "La matanza del domingo: ETA vuelve a la guerra"

Num: 862 Año:XXXIII

Fecha de publicación: 04-08-1979 Página(s):14-15

1980

Autor: López Agudín, Fernando, 1943-

Título: "La escalada de la violencia"

Num: 889 Año:XXXIII

Fecha de publicación: 09-02-1980 Página(s):18-19 